\title{
DISCURSO DE INSTALACION PRONUNCIADO POR EL DR. ROBERTO VERGARA TAMARA, COMO PRESIDENTE DE LA SOCIEDAD COLOMBIANA DE OBSTETRICIA Y GINECOLOGIA, Y PRESIDENTE HONORARIO DEL CONGRESO
}

CUCUTA, 3 DE DICIEMBRE DE 1967

Sr. Ministro de Salud Pública, Dr. Antonio Ordóñez Plaja; Sr. Arzobispo, Pablo Correa León; Sr. Gobernador, Gonzalo Lozano Cárdenas; Sr. Alcal de, Eustorgio Colmenares; Sr. Presidente del Congreso, Dr. Humberto Faillace; Sr. Cónsul de Venezuela; Presidentes Honorarios; Invitados de honor: Luis Castelazo, Carlos MacGregor, Samuel Karchmer, Carlos D. Guerrero, Jorge Ascenzo, Oscar Agüero, Aquiles Sobrero, Gregorio Oclander, Juan J. Poseiro, Carlos Méndez Bauer, Autoridades Militares, Señoras y Señores Congresistas:

Los Directivos de la Sociedad Colombiana, auspiciadora, y, los de la Nortesantandereana de Obstetricia y Ginecología, organizadora del VII Congreso de la Especialidad, tenemos hoy el privilegio de instalar oficialmente las deliberaciones que desarrollarán eminentes figuras nacionales y extranjeras, en cumplimiento a un programa que contempla temas de especial interés, endilgado al beneficio de la mujer infértil y al auxilio de una patria generosa, que por su misma fertilidad -incongruencias de la socio-biología - se está resque- brajando bajo el propio peso de sus mismos hijos.

Los que tenemos la fortuna de estar al servicio de la mujer - LA MUJER ES UNA MAJESTAD- plenamente, concientemente, los que la hemos magnificado como epicentro de nuestras actividades científcias y espirituales, reunidos hace 2 años en Cartagena escogimos las materias que nos ocuparán desde mañana, no por simple casualidad que si hubiese asomo de ella sería más bien serencipidad, neologismo arcaico aprovechado de Antonio Ordóñez Erudito y no Ministro, cosa bien distinta, porque Colombia y América se enrumban definitivamente hacia un mejor destino, después de tantas amarguras, desilusiones y frustraciones hijas del inconsutil idealismo o de la bastarda rivalidad, de los fundadores de nuestras Repúblicas.

Si no participamos activamente en el complejo engranaje de la Gobernación de la República, en el sitio de avanzada que nos corresponde, hombro a hombro con nuestros estadistas, en procura de soluciones pragmáticas con el mismo celo y el mis- 
mo amor que ponemos en devolver la salud a la mujer enferma, nuestras Universidades, nuestras Facultades de Medicina y nuestras Asociaciones Médicas serán meras entelequias que morirán paralizadas en discusiones especulativas abstractas. Por eso y con toda razón discutiremos a espacio, con lo mejor que tenemos en el campo de la Planificación Familiar, el problema de la Trancisión Demográfica en Colombia, que lo consideramos de la mayor entidad en el momento histórico que vive América $y$ el mundo.

Los que me sigan escuchando se quedarán perplejos por la Tesis de mi Discurso. Las cuestiones científicas, que harto rato tenemos para ello, están a cargo de personas más calificadas que yo. Para poder explicarme mejor hagamos de la historia el sustrato sociológico de nuestras ideas.

Muchas veces se ha frustrado el destino histórico de Colombia. Unos dicen que seis y si nosotros no intervenimos seremos los actores de la séptima. La Cultura de San Agustín, se interrumpe con la inmigración de los pueblos Chibchas y Caribes hacia el siglo XII. La cultura Muisca Oriental, se derrumba con la conquista española. La cultura colonial _la de los Criollos y los Españoles- se rompe en los patíbulos y en las guerras cle la Independencia. En 1830 se disuelve la Gran Colombia. En 1903 perdemos a Panamá -Zarpazo de una mano rubia- consecuencia de nuestras guerras civiles, desmembración que no pudimos evitar con patrioteros gestos y frases elocuentes. $Y$ en 1949, después del 9 de Abril perdimos lo que habíamos logrado con una paz tan costosa. El momento actual es el de Frente y la Transformación nacionales, en que unidos todos los Colombianos tratamos de no perecer ante las injurias del medio exterior y por nuestra capacidad volitiva de emitir vigencias propias.

Colombia como todos los pueblos ha tenido un nacimiento histórico y un nacimiento biológico. Vivimos de las generaciones. El sistema según las teorías sociológicas del Inglés Dilthey funciona en base a tres generaciones. De los 30 años a los 45 la de Iniciación. 45 a 60 años la del Predominio y la de 60 y más la de Relevo.

Cada generación tiene su estilo y hace sus contribuciones a la Patria de acuerdo con sus propios matices. Para ubicar la nuestra quisiera recordar las otras. La Generación Heróica y la de los Caudillos. La Generación Costumbrista. La Clásica. La Conciliadora o Republicana y por último, aquí está la nuestra, la llamada Modernista que comienza desde 1920, empeñada en superar los anacronismos del país. Trata de imponer vigencias sociales, inconformismos con un estilo vital de bohemia rebelde, según la frase de Abel Naranjo Villegas. El estilo es erudito. Su consigna es clasista, buscando el reajuste de las capas sociales. Desde 1950 y hasta 1980, prevalecerá esta generación que se ha llamado socializadora porque es eminentemente antiburguesa, siendo casi todos sus dirigentes burgueses. Su estilo vital es el reformismo social, la secularización filosófica, la densidad intelectual y la reacción contra la retórica. El problema social que encaran es el desequilibrio económico, la agitación de masas, la desintegración de los partidos, la Planificación Administrativa, la Planificación Educacional, la Planificación Familiar. Tiene un puro estilo existencial.

Todo lo anterior pudieran ser vaguedades históricas pero tratan de situarnos en la búsqueda de la resolu- 
ción de nuestros problemas sociodemográficos, porque no tenemos un esquema básico de interpretación de los procesos capitales de Colombia y de Latinoamérica, que puedan achacarse exclusivamente a deficiencias estadísticas. Por lo cual es nuestro deber ayudar al Gobierno Nacional en sus planes de transformación, aun cuando no estemos de acuerdo con alguno de los puntos básicos de la política actual.

Nuestra contribución será más acertada mientras mayor sea el acopio de cifras, hipótesis, descripciones e interpretaciones sobre aspectos específicos de historia, sociología, morbilidad, fertilidad, migraciones internas o externas y la composición de la población total según grupo de edades, sexo, ocupación o cualquiera otra categoría.

La situación de Colombia respecto a los otros países de América no es igual en todos sus aspectos; con muchos tienen similitudes. Está exhibiendo una rata de crecimiento vegetativo mayor que el de muchas regiones. No ha tenido tantas corrientes migratorias importantes como Argentina y Chile. Es uniforme el éxodo desde los campos a los grandes centros urbanos sin que las masas desplazadas encuentren ocupación o trabajo. Los complejos son múltiples y escasas las investigaciones en todos los aspectos sociales y demográficos, que es lo que estamos tratando de realizar y por lo cual pedimos el concurso de las gentes pensantes, para no lanzarnos en una campaña del control de la natalidad sin conocer íntimamente las capacidades del país. Campañas que hoy están reclamando por el desequilibrio entre el crecimiento demográfico y el crecimiento del conjunto de la economía, sin contar con verdaderos instrumentos de orientación.
De todas maneras es muy difícil aproximar los coeficientes de natalidad y mortalidad, hasta un punto en que su diferencia que no es otra que la rata vegetativa 0 natural de incremento de la población, sea compatible con las disponibilidades de capital, oportunidades de empleo, higiene, hospitales, salud, seguridad social, y escuelas a que están obligados los gobiernos con las generaciones que arriban a la etapa de la productividad. Pero sea como fuere, debemos hacer una planificación conciente con nuestros principios éticos y morales y nuestras capacidades económicas. Mientras avanzan los planes del Gobierno de la Nación, reforma agraria, estudio a la actividad privada, proyectos de paternidad responsable, medidas tributarias, Reforma Educacional, Erradicación de tugurios, Incrementos de las Exportaciones y tantos otros que ya no somos capaces de retener, recuerdo la reflexión de Konrad Adenauer, lema de su austera existencia: "De varias cosas buenas que haya que hacer, la primera es la que primero se pueda hacer".

Por todos estos razonamientos $y$ por los que habrán de seguir, es que la Directiva de la Sociedad Colombiana de Obstetricia y Ginecología, ha apoyado los programas del Gobierno Nacional y los de la División de Estudios de Población, de la Asociación de Facultades de Medicina.

Constituímos un grupo de especialistas interesados en la solución de los problemas nacionales, por lo cual estamos concientes de las peligrosas implicaciones, que tiene un aumento incontrolado de la población y por ello nos preocupan el aborto inducido, el infanticidio en sus dos formas, puro o encubierto. Las prácticas anticonceptivas populares que ocasionan grave daño al aparato genital. Se 
ha omitido una buena educación sexual. Existe una alta densidad social, que se traduce al desempleo, déficit de vivienda, desnutrición, analfabetismo, alto porcentaje de población dependiente y otras características de los países en vía de desarrollo. El hijo indeseado, será el desadaptado social del futuro. Las altas tasas de natalidad repercuten gravosamente. Alimentar, educar, a estos niños de estratos sociales inferiores, en donde las enfermedades derivadas del hacinamiento, desaseo y desnutrición, son de una alta incidencia en nuestro medio.

Cada día existe un número mayor de hijos ilegítimos, producto de la irresponsabilidad reinante en nuestros diferentes grupos humanos. No podemos negar que por parte de sectores importantes de la opinión pública existe un desconocimiento absoluto, o mal intencionado. Hay posturas obscurantistas retrógradas de demagogos recalcitrantes reaccionarios, pertenecientes a la generación de Relevo, no por sus edades, sino por sus ideas, que aprisionan y amordazan el impulso vital de nuestro futuro desarrollo.

El $75 \%$ de los trabajos de este Congreso son sobre Planificación Familiar. Es que ya se está creando una conciencia Nacional y la expresión feliz de Hernán Mendoza, "La necesidad sentida", es un luminoso heraldo que nos impele a pedir más cursos de adiestramiento para personal Médico y paramédico, sobre Planificación Familiar, Demográfica y Diagnóstico precoz del Cáncer. Que las cátedras de Obstetricia y Ginecología, Pediatría, Medicina Preventiva, hagan una más prolija divulgación de estos temas.

Seguiremos pensando que la Planificación Familiar, concebida con una buena base educativa, en la libertad de la pareja humana para decidir libre y concientemente sobre el tamaño de su familia, ejercitando el intangible derecho de una paternidad responsable, se extienda racionalmente a todos los Colombianos, sin distingos. Que cada cual tenga la información de que hoy carecen, para que así, con libre acceso a los servicios y programas de acción, no tengan, además, otra irrisoria discriminación educacional.

De estas deliberaciones obtendremos las recomendaciones específicas al Gobierno, a las autoridades eclesiásticas y a las Facultades de Medicina.

Sabemos que nuestros puntos de vista nos traerán contrariedades, ninguna de ellas buscada, ni agradables. Pero debemos admitir, sin reticencias, Cira el coetáneo de todas las generaciones es el hombre superior. Para los otros no hay escape posible. "Cada uno tiene su estilo de amar, de pensar, de escribir, de hablar, de trabajar y hasta de orar".

En las ponencias oficiales aprenderemos muchas cosas ignoradas por la vastedad de la literatura actualizable y actualizada. Recordaremos otras olvidadas y saldremos de aquí a nuestras labores habituales, con nuevos conocimientos adquiridos, remozados y optimistas y con la nostalgia de tener que olvidar lo que antes habíamos enseñado y practicado como lo presumiblemente verdadero. Pero, es que es ésta, Señoras y Señores, la filosofía de los Congresos. Cercenarle a lo viejo un poco de oropel inútil, para seguir viviendo con lo que modernizado volverá a morir dentro de algunos años en el inexorable y deletéreo ciclo de la constante evolución científica. 
Aligerados por la brevedad haremos a manera de presentación la sinopsis del trabajo que nos hemos propuesto: Era nuestra intención referirnos, aún cuando fuera incidentalmente, tocando en forma sutil la superficie de la temática que, fraternalmente nos agrupa, pero esa es una ímproba labor que no soy capaz de acometer, porque ya me es difícil nada más que enumerar: En un lustro el estudio de la pareja infértil ha cimentado los conocimientos básicos de los diferentes factores que concurren solos, o unidos las más de las veces para redondear el problema de la infecundidad. Los ha mantenido incólumes o los ha modificado, como en el tubárico. Salpingokimografía, Histerosalpingografía, Ginecografía, Culdoscopia y está avanzando decididamente con los tratamientos de hidrotubaciones, las nuevas técnicas quirúrgicas, Strassman con tubo o Salpingometroplastias, que debemos acometer liberalmente apartándonos de la política de disuadir de la cual todos somos cómplices en mayor o menor grado. La anovulación, los ovarios poliquísticos, sí que han recibido un beneficio tremendo de los adelantos científicos, que constituyen un verdadero impacto renovador. No solo es que se han mejorado los métodos de estudio de la disfunción ovárica sino que el tratamiento con Citrato de Clomifeno o Clomid y la ovulación provocada por el F.S.H. humano y urinario según los trabajos de Genzell, son en algunos casos la manera más segura de aliviar a la mujer afecta de Polimicroquistosis Ovárica, sin Menospreciar la resección cuneiforme, que aún y a pesar de lo anterior, está resistiendo la prueba irrevocable que le otorga el tiempo.

En este momento parecería que todo estaba discurriendo plácidamente.
Principios básicos que se mantienen estáticos, por buenos, aportes nuevos, comprensibles las más de las veces, a pesar de no conocerse muy claramente el sitio de actuación en el complejo eje hipotálamo - hipofisiario - ovárico. Y de repente aparecen, como fantasmas de la imaginación a perturbar nuestra hipotética tranquilidad, las aglutininas, los anticuerpos y las funestas reacciones de inmunización. Y si esto fuera poco, que ya es mucho, los avances en el conocimiento del carácter y desarrollo de los espermatozoides y las causas de la teratogenesis.

Así quería yo seguir discurriendo, versátil, $y$ a veces incisivo $y$ profundo, ignorante y superficial, las más de las veces, ayudado solo por mi astucia y mi voluntad de servicio, en todas las cuestiones. Infecciones Pélvicas, Tumores Trofoblásticos, Carcinoma Uterino, Hipofibrinogenemias, Toxicosis Gravídica, Eclampsia, y tantos otros más, pero abordaría la orilla opuesta, cojitranco, renqueando apoyado en el cansancio de un esfuerzo inútil, sin poder explicar la magnitud de la apetencia.

En Marzo del año entrante, la Sociedad Colombiana de Obstetricia y Ginecología, cumplirá 25 años de fundada. Un grupo de Profesores y Jefes de Clínicas iniciaron sus labores con un carácter eminentemente científico, pero con posterioridad tuvieron que adicionarle el gremial, porque la generación socializadora, los urgía a defender no solo su patrimonio científico y espiritual sino el económico. Y es así como es una de las pocas que en Colombia mantiene contratos de trabajo con el ICSS. en forma tal, que sus especialistas prestando sus servicios en Institutos de Seguridad Social, se proyectan, con sus excelentes cualidades hacia una comunidad, que los aprecia, los quiere, los esti- 
ma y los reclama. Hace 20 años fundaron la Revista de la Sociedad, que ha realizado la imponderable hazaña de mantenerse a flote viva, circulante, pujante, cada vez mejor, en un mar de tinta en donde se han ahogado al garete tantas publicaciones que merecían puerto seguro.

Estamos suscritos a las publicaciones científicas de la especialidad y con todas ellas mantenemos canje. Somos miembros fundadores y afiliados a Sociedades Internacionales, como la F.I.G.O. y FLASOG. La Sede de la Secretaría Permanente está en Bogotá, es su Presidente Arturo Aparicio Jaramillo y el Secretario General Fernando Sánchez Torres.

En el transcurso de estos años hemos realizado VII Congresos Nacionales y uno Latinoamericano y muchos de nuestros miembros han participado en forma decorosa en Congresos Internacionales, con valiosas contribuciones o con Ponencias en representación Oficial de Colombia.

Toda esta honrosa y meritoria tradición se ha mantenido intacta y las Directivas actuales con clara visión de responsabilidad y deberes, la entrega con limpias manos a la Federación de Sociedades de Obstetricia y Ginecología, que fundaremos mañana, ante Notario Público, en el histórico templo de la Villa del Rosario de Cúcuta, según la frase-bandera de Alberto Duarte Contreras.

La Academia Nacional de Medicina, me encargó presentar a la honorable consideración de ustedes el proyecto aprobado ya por una comisión de la cual hice parte. De dotar a la naciente Federación de un escudo o símbolo, que traduzca nuestras embrionarias manifestaciones culturales prehistóricas. Se trata del "Obispo" una gigantesca escultura, una estatua monumental de más de 4 metros de altura, que según el académico Andrés Soriano Lleras, de acuerdo con las descripciones de Cuervo Márquez y Preusd y la posición ortodoxa de Duque-Gómez y Codazzi, la parte superior del "Obispo" es la representación de un Partero o Partera, que sostiene de las piernas un niño recién nacido. La figura inferior del dicho "Obispo", bien pudiera corresponder a la madre.

Yo rogaría a la Junta de Delegatarios de la Federación de Sociedades de Obstetricia y Ginecología, que meditaran serenamente el asunto que se les propone por múltiples motivos que acuden fervorosos: El escudo del Colegio Colombiano de Cirujanos, representa un instrumento quirúrgico de la tribu Quimbaya que data del año 1400. Y la figura de Cerámica, con que fueron obsequiados los asistentes al mencionado Congreso de $\mathrm{Ci}$ rujanos, representa al curandero de la misma mencionada agrupación tribal Quimbaya y ha sido adoptada como símbolo del médico Colombiano. Y está bien que así sea. Es una refrescante manifestación de Independencia. Siempre estamos apegados a lo foráneo, a lo exótico. Nunca hemos tenido originalidad, por lo endeble de nuestras raíces primigenias, como traté de explicarlo al iniciar este discurso.

Somos cambiantes, inestables, perecederos y fugaces porque no tenemos una auténtica cultura, prehistórica, como sí la ostentan, Méjico, con Moctezuma y Perú con Atahualpa y Manco-Capac. Tan siquiera, y por soslayo, mostremos algo auténtico, algo nuestro, como esta gigantesca estatua, escultura monumental de 4 metros de altura, que nos redima de este rubor burgués que tanto nos agobia. 
Señores Congresistas aquí en la ciudad de Cúcuta, según la más añeja tradición fué el Indio Guaimaral, primogénito del Cacique Cúcuta Dominador de las tribus que habitaban las márgenes del Coquivacoa, quien primero exploró las regiones del Catatumbo para que en sus feraces valles se fundara en 1733 la Villa de San Luis de Cúcuta, por generosa donación que hiciera Doña Juana Rangel de Cuéllar de sus propiedades denominadas Tonchalá. Aquí en la ciudad de Cúcuta, digo, hago un alto en este punto y hora de mi discurso e invoco la memoria impoluta de nuestros pioneros y maestros: José Ignacio Quevedo, el primero, 1844 en realizar en Ana Joaquina Echeverría de T. una Cesárea con madre y feto vivos. Leoncio Barreto, quien practica la segunda Ooforectomía con éxito en América Latina, José J. de la Roche, Juan B. Montoya y Flórez, Pablo García Aguilera, Eliseo Montaña, Rafael Ucrós, Libardo Rivas, José María Buendía y Miguel Rueda Acosta, ante quienes me excuso, por este escindido discurrir porque no soy ni siquiera un modesto epígono de sus virtudes. $Y$ en este solemne momento no menciono a José del Carmen Acosta, porque él discreto, sapiente y silencioso, con su figura austera vigila, protege y guarda su heredad. No hablo aquí de ninguna de las esposas de estos varones ilustres, porque ellas como los manantiales cristalinos que refrescan la tierra, se mantienen esquivas en la suavidad de su rumor.

En nombre de mis compañeros de Mesa Directiva, Guillermo Navas An- gel, Ricardo Rueda González, y Enrique Duplat, agradezco al Comité Ejecutivo del VII Congreso, Doctores Humberto Faillace, Eduardo Pérez Gómez, Luis Luzardo, Alberto Duarte Contreras y Ramiro Zúñiga Gamboa, ésta demostración de esfuerzo, constancia, desvelos y trabajos, que hicieron posible con la sola virtud de vuestro empeño, la numerosa concurrencia de tantas personalidades ilustres, nacionales y extranjeras, para que con la increíble cifra de diez invitados de honor esta reunión, de nacional, se haya trocado en internacional.

Perdonadme esta larga exposición. Los culpables son otros, aquellos que en una exuberante manifestación de benevolencia le hicieran este honroso encargo a persona tan flaca, insolvente $y$ ayuna de merecimientos $y$ tan abundosa en necedades y defectos.

Señoras y Señores, sean bienvenidos a esta ciudad de Cúcuta aquilatada como joya preciosa de Colombia, por la gallarda valentía de sus hombres y la virtud y señorío de sus mujeres. Cada uno de los que hemos intervenido en la realización de este Congreso algo hizo, poco o mucho, pero si alguien merece ser alabado por el éxito que de seguro habremos de obtener, ese es Alberto Duarte Contreras. Para tí solo hay un adjetivo posible. Le he encontrado en la cantera inagotable del idioma: Hijodalgo, porque en el mayorazgo de tu alcurnia atesoras las cimeras virtudes de los hombres nortesantandereanos.

Muchas gracias. 